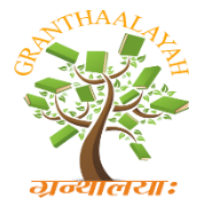

\author{
INTERNATIONAL JOURNAL OF RESEARCH - \\ GRANTHAALAYAH \\ A knowledge Repository
}

Science

\title{
DETERMINATION OF ASPHALT CONCRETE VISCOSITY BY THE FOUR-POINT BENDING TEST
}

\author{
J. R. Spínola ${ }^{* 1}$, A. C. L. da Silva ${ }^{1}$, A. P. Torres ${ }^{1}$, C. A. Frota ${ }^{1,2}$, H. O. Frota ${ }^{1,3}$ \\ ${ }^{*} 1,1$ Geotechnical Research Group (GEOTEC) - Federal University of Amazonas, Brazil \\ ${ }^{2}$ Department of Civil Engineering - Federal University of Amazonas, Brazil \\ ${ }^{3}$ Department of Physics - Federal University of Amazonas, Brazil
}

\begin{abstract}
In this work, a model for the dynamical four-point bending test is present, with particular emphasis on application to an asphalt concrete (AC) composite, a viscoelastic material, based on the EulerBernoulli theory, which approaches an equation where the Young modulus $\mathrm{E}$ can be substituted by the operator $(\mathrm{E}+\gamma \partial / \partial \mathrm{t})$, where $\gamma$ is an internal damping parameter associated to the binder viscoelasticity and $t$ is the time. As course aggregate in the composition of the AC mixture, the sintered aggregate of calcined clay was used, interesting to be employed as an alternative to the lack of natural course aggregate in some regions of the planet, where the presence of sedimentary rocks prevails. The results indicated that $\gamma$ decreases with the temperature and loading frequency and the apparent noise in the stiffness versus strain curve is resulted from the natural vibration mode of the beam.
\end{abstract}

Keywords: Four-Point Bending; Viscoelasticity; Vibration Mode.

Cite This Article: J. R. Spínola, A. C. L. da Silva, A. P. Torres, C. A. Frota, and H. O. Frota. (2019). "DETERMINATION OF ASPHALT CONCRETE VISCOSITY BY THE FOUR-POINT BENDING TEST." International Journal of Research - Granthaalayah, 7(9), 415-426. https://doi.org/10.29121/granthaalayah.v7.i9.2019.627.

\section{Introduction}

The four-point bending test has been exhaustively used to study the complex stiffness modulus of viscoelastic materials, such as concrete asphalt (CA) composite [1-5], as well as the fatigue processes that take place in these materials [6-12]. Both are very important inputs to develop pavement designs $[13,14]$. The results of this test is interpreted using the Euler-Bernoulli equation $[15,16]$, which originally was proposed to study elastic beams with the cross dimensions much smaller than the longitudinal dimension. In the dynamical four-point bending, two equal sinusoidal loads are applied to one-third of the beam extremities, at whose center the stiffness and the strain are measured. For a linear viscoelastic material, at each time, the complex stiffness modulus is related to the strains via the loading frequency and the phase angle. This represent the lag time $\varphi$ between stress and strain by the relation $E^{*}=\left(\sigma^{*}(t) / \varepsilon^{*}(t)\right)$, where the stress $\sigma^{*}(t)=\sigma_{o} \exp (i \omega t)$, 
the strain $\varepsilon^{*}(t)=\varepsilon_{o} \exp (i \omega t-\varphi)\left(\sigma_{o}\right.$ and $\varepsilon_{o}$ are the maximum stress and strain, respectively), and the angular frequency $\omega$ is related to the load frequency $f$ by $\omega=2 \pi f$. As a complex number, $E^{*}$ can be written as $E^{*}=E_{1}+i E_{2}$ and $\varphi=\arctan \left(E_{1} / E_{2}\right)$ [17]. Physically, the real component $E_{1}$ represents the elastic propriety of the material, and the imaginary part $E_{2}$ its viscous behavior. Therefore, $E_{1}$ is associated with the capability of the material to storage energy and $E_{2}$ with its capability to dissipate energy. For this reason, $E_{1}$ and $E_{2}$ are also known as storage and dissipation modulus, respectively.

In the usual Euler-Bernoulli model for the four-point bending test, the viscosity behavior of the material in general is not take into account. The present work aims to introduce the viscous properties in this model as an internal damping parameter, using the simple Kelvin-Voigt model [18], to develop an expression for the displacement at the center of the beam of the four-point bending test in the steady state regime. In particular, it is important to emphasize that this approach is meaningful to represent this displacement by only the first term of the expansion on the natural vibration modes of the beam. Moreover, the model was applied to a concrete asphalt composite, whose course granular material is constituted by sintered aggregate of calcined clay, as an alternative to the lack of course aggregate natural material in the word regions where the presence of sedimentary rocks prevails. It has been observed that for concrete asphalt composite the damping parameter of the material decreases with temperature and loading frequency. The apparent noise that appears in the stress-strain curve is really a consequence of the natural mode vibration of the beam. For high temperature, the frequency of this vibration is approximately equal to the frequency of the vibration mode.

\section{Theory of The Four-Point Bending Dynamic Bending Test for Viscoelastic Material}

The four point bending test apparatus consists of a prismatic beam with four support points. Two of them are located at one third of the ends, which are used to the loading. The other two are at the ends, of the articulated type, which can rotate without promote any displacement in the direction of the applied load, as shown in Fig. 1. In this structural form, the central span of the beam is under pure bending.

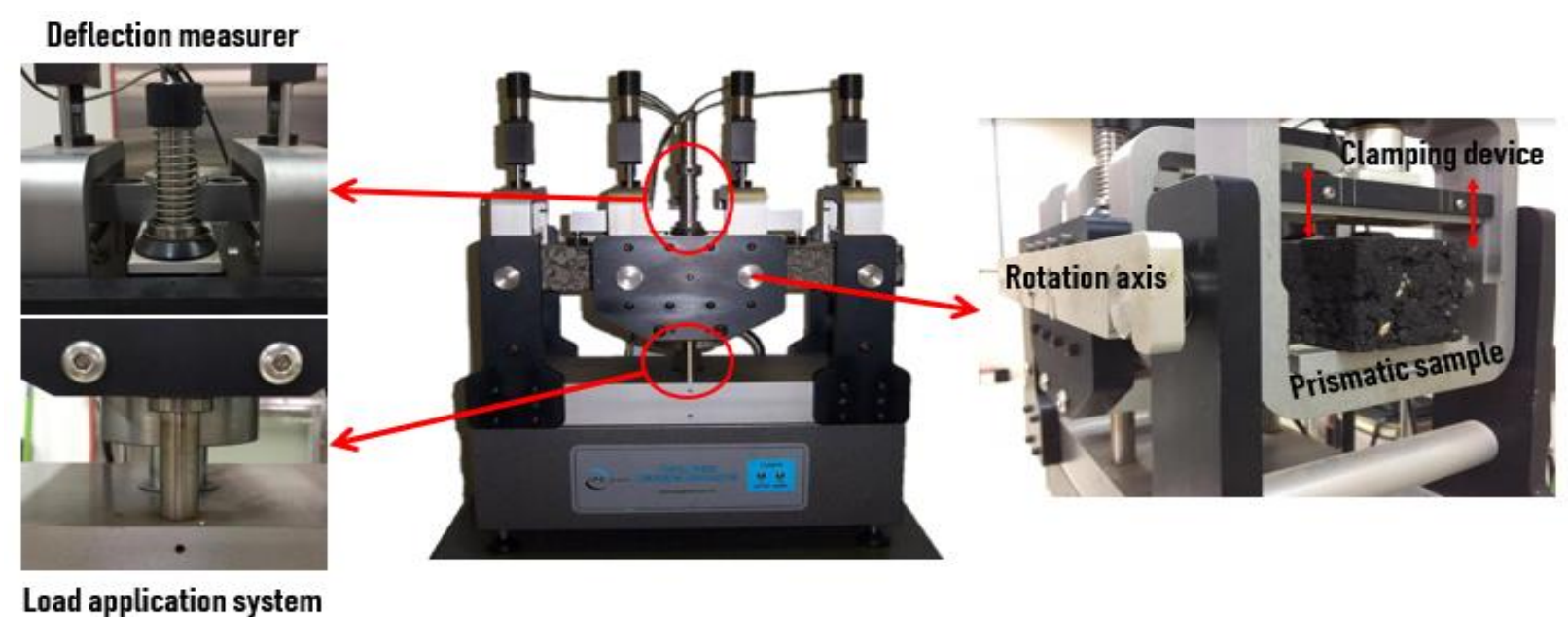

Figure 1: Four-point bending apparatus used in this research with equipment mechanisms detailed. 
The loading produces a uniform tension state and a constant bending moment along the central part of the beam. Thus, in this region, there are no shear stresses, only pure bending. This condition approximates the experimental arrangement to the general hypotheses adopted by Euler-Bernoulli to calculate the deformations in a beam. In addition, deformations in the center of the prismatic specimen are free of effects arising from points of stress concentration, since the loads are concentrated on a third of the ends. In short, this four-point experimental arrangement decreases the uncertainties and propagation of errors and reduces the results dispersion.

Given this concerns, let us consider an uniform elastic beam with length $L$, cross section $A$ and mass density $\rho$, over which is applied a vertical load $q(x, t)$, as a function of the coordinate $x$, along of the beam axis, and of the time $t$. In the four-point dynamic bending test, a sinusoidal load is applied to one-third of both extremities of the beam, as shown in Fig. 2. This load is represented as the sum of two Dirac delta functions centered at $x=L / 3$ and $x=2 L / 3$, as follows:

$q(x, t)=\frac{q_{0}}{2}\left[\delta\left(x-\frac{L}{3}\right)+\delta\left(x-\frac{2 L}{3}\right) \sin (\omega t).\right]$

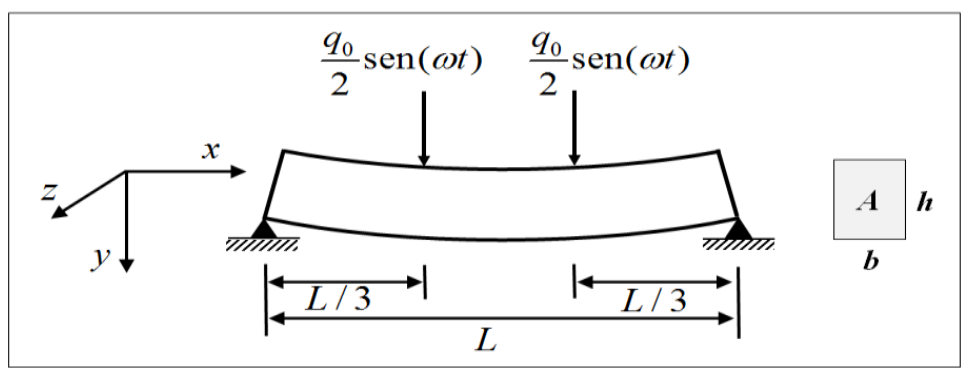

Figure 2: Pictorial representation of the four points bending test. A sinusoidal load $q_{o} \sin (\omega t) / 2$ is applied to a beam of length $L$ and cross section $A$, with width $b$ and height $h$, at $x=L / 3$ and $x=2 L / 3$.

The Euler-Bernoulli Eq. [8] for an elastic beam is written in the form of Eq. (2):

$\frac{\partial^{2}}{\partial x^{2}}\left(E I \frac{\partial^{2} y(x, t)}{\partial x^{2}}\right)+\rho A \frac{\partial^{2} y(x, t)}{\partial t^{2}}=q(x, t)$,

Where $y(x, t)$ is the transverse displacement at coordinate $x$ and time $t, E$ is the Young modulus and $I$ is the known inertia moment of the cross section area, with $b$ and $h$ the width and the height of the beam, respectively. Using the variable separation method, taking $y(x, t)=Y(x) T(t)$, the natural vibration modes are obtained for $q(x, t)=0$ under the boundary conditions:

$Y(0)=Y(L)=0$;

$\partial^{2} Y(0) / \partial^{2} x=\partial^{2} Y(L) / \partial^{2} x=0$, which are given by $Y_{n}(x)=\sin \left(\beta_{n} x\right)$, em que $\beta_{n}=n \pi / L$, com $n=1,2, \ldots)$ associated to the angular frequency:

$$
\omega_{n}=\left(\frac{n \pi}{L}\right)^{2} \sqrt{\frac{E I}{\rho A}} .
$$


The general solution of Eq. (2) for $q(x, t)=0$ can be obtained in terms of those natural modes of vibration. In order to introduce the viscosity in the model given by Eq. (2), we can use the simplest viscoelastic model of Kelvin-Voigt [10], for which the relation between the tension and deformation is given by:

$$
\sigma=\left[E+\gamma \frac{\partial}{\partial t}\right] \varepsilon
$$

Where $\gamma$ is an internal dumping parameter of the material due to its viscosity. Substituting $E$ for $E$ $+\gamma \partial / \partial t$ into Eq. (2), we obtain the Euler Bernoulli equation for a viscoelastic uniform beam represented by:

$$
E I \frac{\partial^{4} y(x, t)}{\partial x^{4}}+\gamma I \frac{\partial^{4}}{\partial x^{4}} \frac{\partial}{\partial t} y(x, t)+\rho A \frac{\partial^{2} y(x, t)}{\partial t^{2}}=q(x, t)
$$

whose solution can be written in terms of the natural vibration modes $Y_{n}(x)$ as:

$$
y(x, t)=\sum_{n=0}^{\infty} c_{n}(t) Y_{n}(x)
$$

where $c_{n}(t)$ is a time dependent coefficient to be determined.

Substituting Eq. (6) into Eq. (5), and using the orthogonality properties of the natural vibration modes $\left(\delta_{\mathrm{m}, \mathrm{n}}\right.$ is the delta of Kronecker), the coefficients $c_{n}(t)$ are obtained from the solution of the differential equation:

$$
\frac{d^{2}}{d t^{2}} c_{n}(t)+2 \eta_{n} \omega_{n} \frac{d}{d t} c_{n}(t)+\omega_{n}^{2} c_{n}(t)=\frac{Q_{n}(t)}{\rho A}
$$

with the following definitions:

$$
\begin{aligned}
& \eta_{n}=\frac{\gamma}{2 E} \omega_{n} \\
& Q_{n}(t)=\frac{2}{L} \int_{0}^{\infty} Y_{n}(x) q(x, t) d x .
\end{aligned}
$$

Using the Laplace transform and the convolution theorem [19], we find that:

$$
c_{n}(t)=\frac{2}{M} \frac{1}{\omega_{n} \sqrt{1-\eta_{n}^{2}}} \int_{0}^{L} d u Y_{n}(u) \int_{0}^{t} d \tau q(u, \tau) e^{-\eta_{n} \omega_{n}(t-\tau)} \sin \left(\omega_{n} \sqrt{1-\eta_{n}^{2}}(t-\tau)\right)
$$

where $M=\rho A$ is the beam mass. 
Inside the integrand in the spatial coordinate $x$ of Eq. (10), there is the Dirac delta function, which appears in the load $q(x, t)$ given by Eq. (1). Substituting Eq. (1) into Eq. (10) and using the delta function property $\int f(x) \delta\left(x-x_{0}\right) d x=f\left(x_{0}\right)$, we find:

$$
c_{n}(t)=\frac{q_{0}}{M} \frac{\left[Y_{n}(L / 3)+Y_{n}(2 L / 3]\right.}{\sqrt{\left(\omega_{n}^{2}-\omega^{2}\right)^{2}+\left(2 \eta_{n} \omega_{n} \omega\right)^{2}}} \times\left[\sin \left(\omega t-\varphi_{n}\right)-\frac{\omega e^{-\eta_{n} \omega_{n} t}}{\sqrt{1-\eta_{n}^{2}}} \sin \left(\omega_{n} \sqrt{1-\eta_{n}^{2}} t+\theta_{n}\right)\right],
$$

Where

$$
\begin{aligned}
& \varphi_{n}=\tan ^{-1} \frac{2 \eta_{n} \omega_{n} \omega}{\omega_{n}^{2}-\omega^{2}} \\
& \theta_{n}=\tan ^{-1} \frac{2 \eta_{n} \omega_{n}^{2} \sqrt{1-\eta_{n}^{2}}}{2 \eta_{n}^{2} \omega_{n}^{2}-\omega^{2}}
\end{aligned}
$$

The first and the second terms inside the bracket, in Eq. (11), represent the steady and the transient states, respectively. The steady state regime occurs in the limit $t \rightarrow \infty \quad\left(e^{-\eta_{n} \omega_{n} t} \rightarrow 0\right)$, for which the transient term disappear. In this limit, $c_{n}(t)$ becomes:

$$
c_{n}(t)=\frac{q_{0}}{M}\left[Y_{n}\left(\frac{L}{3}\right)+Y_{n}\left(\frac{2 L}{3}\right)\right] \frac{\sin \left(\omega t-\varphi_{n}\right)}{\sqrt{\left(\omega_{n}^{2}-\omega^{2}\right)^{2}+\left(2 \eta_{n} \omega_{n} \omega\right)^{2}}} .
$$

From Eq. (6) and Eq. (14), the displacement at the center of the beam $(x=L / 2)$ is written as:

$$
y\left(\frac{L}{2}\right)=\frac{q_{0}}{M} \sum_{n=1}^{\infty} \kappa_{n} \frac{\sin \left(\omega t-\varphi_{n}\right)}{\sqrt{\left(\omega_{n}^{2}-\omega^{2}\right)^{2}+\left(2 \eta_{n} \omega_{n} \omega\right)^{2}}},
$$

where

$$
\kappa_{n}=Y_{n}\left(\frac{L}{2}\right)\left[Y_{n}\left(\frac{L}{3}\right)+Y_{n}\left(\frac{2 L}{3}\right)\right] \sin \left(\frac{n \pi}{2}\right)\left[\sin \left(\frac{n \pi}{3}\right)+\sin \left(\frac{2 n \pi}{3}\right)\right]
$$

The peculiar characteristic of the loading positions in the four point bending test, which are equally distributed at $x=L / 3$ and $x=2 L / 3$, produces interesting values for $\kappa_{n}$. It is $\sqrt{3}$ for $n=1$ and is equal to zero for the next three values of $n(n=2,3,4)$. This means that for the first four modes of natural vibration of the beam, only the first mode is excited. The next vibration modes to be excited are the fifth and the seventh, with $\kappa_{n}=-\sqrt{3}$, since the sixth mode is also not excited. Increasing $n, \kappa_{n}=0$ for $n=8,9,10$ and 12 , and becomes $\sqrt{3}$ when $n$ equals to 11 and 13 . In general, $\kappa_{n}$ is represented by the following relations: 
$\kappa_{n}= \begin{cases}\sqrt{3} & \text { for } n=1 \\ (-1)^{m} \sqrt{3} & \text { for } n=6 m \pm 1, \text { with } m \in \mathrm{N} \\ 0 & \text { other than above. }\end{cases}$

In other words, the terms of the series given by Eq. (15) are different of zero if $n=1$ or if $n$ is a prime number or multiple of prime numbers greater than $3(n=6 m \pm 1>3$, with $m \in \mathrm{N})$, where $\mathrm{N}=$ $\{1,2,3,4,5,6 \ldots\}$ represents the set of natural numbers.

From the above considerations, it was verified that, for the usual frequency used in the four-point bending test, which varies from 1 to $20 \mathrm{~Hz}$, a good approximation to the displacement at the center of the beam is achieved, only take into account the first term of the series given by Eq. (15). In this approach, Eq. (15) becomes:

$$
y\left(\frac{L}{2}\right)=\frac{\sqrt{3} q_{0}}{M} \frac{\sin \left(\omega t-\varphi_{1}\right)}{\sqrt{\left(\omega_{1}^{2}-\omega^{2}\right)^{2}+\left(2 \eta_{1} \omega_{1} \omega\right)^{2}}} .
$$

In order to corroborate with that statement, Fig. 2 illustrates the displacements at the center of the beam as a function of time $y(L / 2, t)$, that were obtained using Eq. (15) (black solid line) and Eq. (18) (red solid circle). For sake of numerical calculation, the same parameters were used in the experimental four-point bending tests, which will be presented in the next section. The results obtained from Eq. (18), where we take only the first term of the series given by Eq. (15), are in good agreement with the results obtained from this complete series.

\section{Materials and Methods}

The beams used in the four-point bending tests were made of asphalt concrete composite, a viscoelastic material, as shown in Fig. 3, which contains the sintered aggregate of calcined clay (SACC) as a coarse aggregate, sand (fine aggregate), Portland cement (filler) and asphalt binder AC 50/70. The use of SACC as coarse aggregate is due to its potential for employment in construction of roads located in regions of the planet where shortage of stony material and abundance of clay material. The physical characteristics of the composite participating materials respected ASTM and AASHTO protocols.

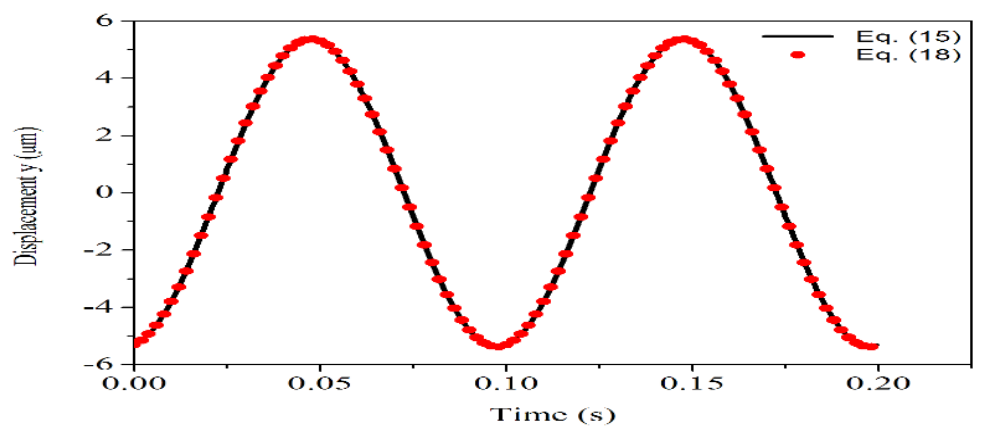

Figure 2: Displacement as a function of time given by Eq. (15) (black line) and Eq. (18) (red circle), which presented very good agreement. 


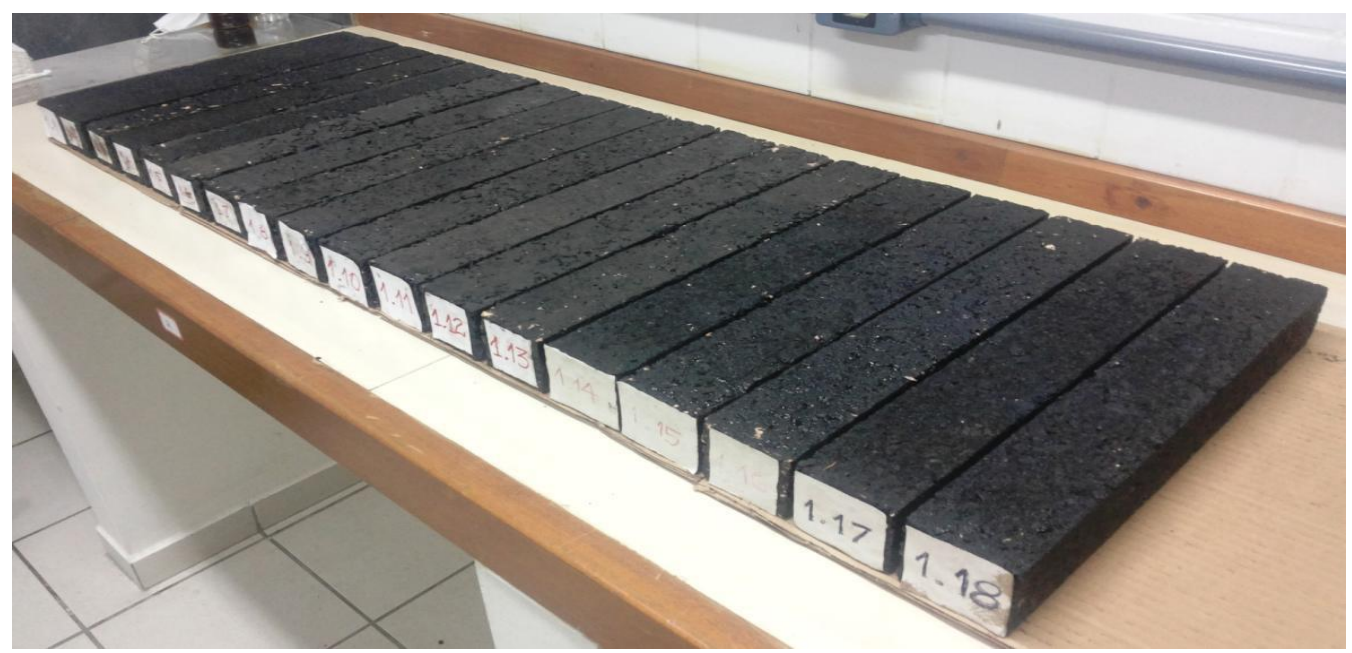

Figure 3: Prismatic specimens (beams) tested in this study.

The mechanical characteristics of the CA composite were performed with the four-point bending test, which eighteen prismatic beams were experimented, with the following average dimensions: length $L=400.00 \mathrm{~mm}$, width $b=65.40 \mathrm{~mm}$ and height $h=51.64 \mathrm{~mm}$. The values of the stiffness $E^{*}$ and phase angle $\varphi$ were conducted under four different applied loading frequencies $1,3,10$ and $20 \mathrm{~Hz}$, and seven different temperatures, varying from 25 to $55^{\circ} \mathrm{C}$, with increments of $5{ }^{\circ} \mathrm{C}$, using strain controlled mode at a deformation ratio of $50 \mu \mathrm{m} / \mathrm{m}$. The experimental program followed EN 12697-26 protocols [5].

\section{Results and Discussions}

\subsection{Materials and Mineral Dosage Characteristics}

The physical characteristics of the aggregates employed on concrete asphalt (CA) composite are presented in Table 1 (coarse aggregate), Table 2 (fine aggregate) and Table 3 (volumetric parameters). According to Superpave methodology, the mineral dosage is detailed on Table 4.

Table 1: Coarse aggregate characterization.

\begin{tabular}{|l|l|l|}
\hline Tests & Component & \multirow{2}{*}{ Standard } \\
\cline { 2 - 2 } & \multicolumn{1}{|c|}{ SACC } & \\
\hline Bulk specific gravity, Gsb $\left(\mathrm{g} / \mathrm{cm}^{3}\right)$ & 1.855 & ASTM C 127 \\
\cline { 1 - 1 } $\begin{array}{l}\text { Bulk specific gravity in the saturated surface dry condition, } \\
\text { Gsbssd }\left(\mathrm{g} / \mathrm{cm}^{3}\right)\end{array}$ & 2.133 & \\
\cline { 1 - 2 } Apparent Specific Gravity, Gsa $\left(\mathrm{g} / \mathrm{cm}^{3}\right)$ & 2.571 & \\
\cline { 1 - 2 } Absorption $(\%)$ & 15.0 & \multirow{2}{*}{ AASHTO T 19 } \\
\cline { 1 - 2 } Loose Unit Weight, Wul $\left(\mathrm{kg} / \mathrm{m}^{3}\right)$ & 1062.0 & \\
\hline Rodded Unit Weight, Wur $\left(\mathrm{kg}^{3} \mathrm{~m}^{3}\right)$ & 1126.4 & ASTM D 5100 \\
\hline Adhesion & Satisfactory & \\
\hline
\end{tabular}


Table 2: Fine aggregate characterization.

\begin{tabular}{|l|l|l|}
\hline Tests & Component & \multirow{2}{*}{ Standard } \\
\cline { 2 - 2 } & \multicolumn{1}{|c|}{ Sand } & \\
\hline Bulk specific gravity, Gsb $\left(\mathrm{g} / \mathrm{cm}^{3}\right)$ & 2.632 & \\
\cline { 1 - 2 } $\begin{array}{l}\text { Bulk specific gravity in the saturated surface dry } \\
\text { condition, Gsbssd }\left(\mathrm{g} / \mathrm{cm}^{3}\right)\end{array}$ & 2.692 \\
\cline { 1 - 2 } Absorption $(\%)$ & 0 & \\
\hline Rodded Unit Weight, Wur $\left(\mathrm{kg} / \mathrm{m}^{3}\right)$ & 1675.9 & \multirow{2}{*}{ AASHTO T 19 } \\
\hline Adhesion & Satisfactory & \\
\hline
\end{tabular}

Table 3: Volumetric parameters.

\begin{tabular}{|c|c|c|c|}
\hline \multirow[t]{2}{*}{ Parameters } & \multirow[t]{2}{*}{ Unit } & Material & \multirow[t]{2}{*}{ Standards } \\
\hline & & SCCA mixture & \\
\hline Binder content & \multirow[t]{4}{*}{$\%$} & 10.9 & \multirow[t]{2}{*}{ ASTM D 1188} \\
\hline Air voids, $\mathrm{Va}$ & & 4.0 & \\
\hline Voids in mineral aggregates, VMA & & 16.6 & \multirow[t]{2}{*}{ ASTM D 2041} \\
\hline Voids filled with asphalt, VFA & & 75.0 & \\
\hline
\end{tabular}

Table 4: AC mixture composition with SCCA.

\begin{tabular}{|l|l|lr|}
\hline Components & Percentage content (\%) & \multicolumn{1}{|c|}{ Standard } \\
\hline SCCA & 62.0 & Superpave guidelines: Strategic & Highway \\
Sand & 34.0 & Research Program (SHRP) & \\
Portland & 4.0 & & \\
cement & 10.9 & & \\
AC 50/70 & & & \\
\hline
\end{tabular}

\subsection{Mechanical Characterization}

The mechanical parameters of the CA composite were performed with the four-point bending test equipment. The eighteen samples were tested. However, in order to respect the EN 12697-26 [5] guidelines, those samples that presented variation of up to $3 \%$ when repeating the first $1 \mathrm{~Hz}$ frequency, were discarded. Table 5 shows the results of the stiffness $E^{*}$, in MPa, and the phase angle $\varphi$, in degrees.

Table 5: Stiffness parameters as a function of the load frequency $f(\mathrm{~Hz})$ and temperature $\mathrm{T}\left({ }^{\circ} \mathrm{C}\right)$.

\begin{tabular}{|l|l|l|l|l|l|l|l|l|l|}
\hline \multirow{2}{*}{$\left.\Gamma \Gamma^{\circ} \mathrm{C}\right]$} & \multicolumn{7}{|c|}{$f[\mathrm{~Hz}]$} \\
\cline { 2 - 9 } & \multicolumn{2}{|c|}{1} & \multicolumn{2}{|c|}{3} & \multicolumn{2}{c|}{10} & \multicolumn{2}{c|}{20} \\
\hline & $E^{*}(\mathrm{MPa})$ & $\varphi\left({ }^{\circ}\right)$ & $E^{*}(\mathrm{MPa})$ & $\varphi\left({ }^{\circ}\right)$ & $E^{*}(\mathrm{MPa})$ & $\varphi\left({ }^{\circ}\right)$ & $E^{*}(\mathrm{MPa})$ & $\varphi\left({ }^{\circ}\right)$ \\
\hline 25 & 1302.0 & 22.4 & 1608.0 & 22.0 & 1953.4 & 16.4 & 1998.2 & 14.4 \\
\hline 30 & 1048.6 & 24.5 & 1312.6 & 22.7 & 1649.8 & 23.0 & 1776.6 & 20.0 \\
\hline 35 & 712.6 & 30.1 & 940.4 & 30.1 & 1211.6 & 31.7 & 1268.2 & 31.7 \\
\hline 40 & 399.6 & 37.0 & 555.4 & 42.9 & 751.8 & 33.5 & 763.4 & 38.7 \\
\hline 45 & 235.4 & 40.3 & 331.4 & 42.1457 .4 & 40.2 & 534.0 & 56.9 \\
\hline 50 & 173.6 & 40.5 & 241.8 & 42.3 & 328.6 & 47.7 & 384.6 & 73.2 \\
\hline 55 & 107.0 & 39.6 & 150.2 & 42.3 & 202.0 & 50.0 & 351.6 & 83.5 \\
\hline
\end{tabular}


From this table, results indicated that, for fixed frequency, the stiffness decreases with the temperature, and for fixed temperature, the stiffness increases with frequency. On other hand, for fixed frequency, the phase angle increases with temperature. Similar behavior was evidenced by Melo, 2014 [20]. The author obtained the same stiffness parameters for a hot-mix asphalt mixture also under four-point bending tests. However, in despite of the resembling employed methodology, different mixture components were used, which were crushed stone and gravel as coarse aggregate, stone dust as fine aggregate and hydrated lime as filler. For comparative reasons, Fig. 4 illustrates the found patterns ( $E^{*}$, Fig. 4(a) and $\varphi$, Fig. 4(b)), considering the temperatures that coincided with those approached in this study $\left(25\right.$ and $\left.30^{\circ} \mathrm{C}\right)$.

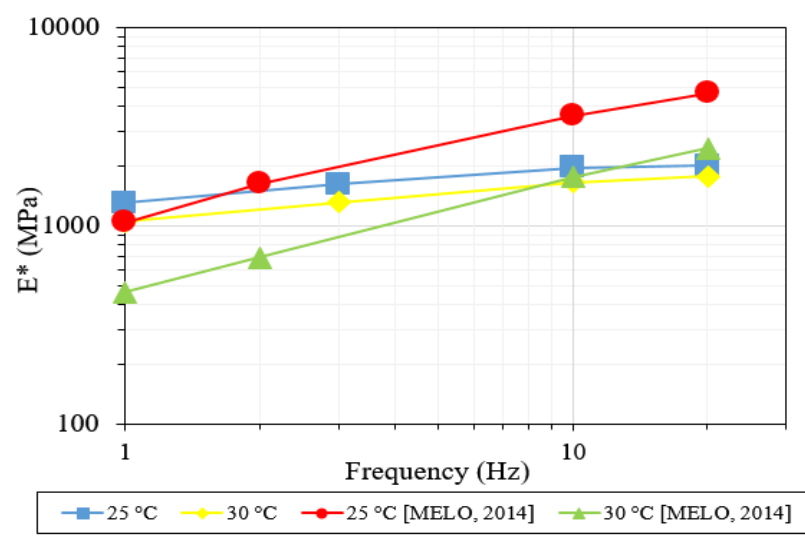

a)

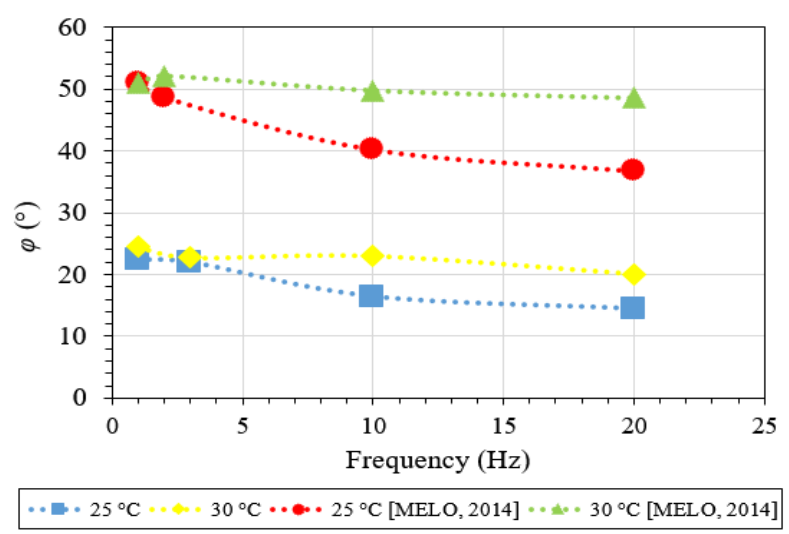

b)

Figure 4: a) Comparison between the dynamic modulus $E^{*}(\mathrm{MPa})$ and phase angle $\varphi\left({ }^{\circ}\right)$ obtained under different loading frequencies, at 25 and $30{ }^{\circ} \mathrm{C}$, for this study and Melo (2014).

\subsection{Determination of Viscosity Coefficient}

In this section, using the data shown in Table 5, the calculation of the viscosity coefficient $\gamma$ introduced in the Euler-Bernoulli model in Eq. (5) is presented, as a way to represent the internal viscosity of the CA composite in the four-point bending test. From Eq. (18), the phase $\varphi$ can be approximated of the displacement in relation to the force, which is described together with the stiffness $E^{*}$ in Table 5, by $\varphi=\varphi_{1}$ corresponding to the first vibration mode of the beam. Using Eqs. (3), (8) and (12), the viscosity coefficient $\gamma$ is given by:

$$
\gamma=\frac{E}{2 \pi f}\left(1-\frac{L^{4}}{\pi^{2}} \frac{4 \rho A}{E I} f^{2}\right) \tan \left(\varphi_{1}\right),
$$

Fig. 5(a) shows the viscosity coefficient $\gamma$ (MPa.s) as a function of temperature, for load frequency of 1 (black), 3 (red), 10 (blue) and $20 \mathrm{~Hz}$ (green). A visual analysis conduct us to conclude that the parameter $\gamma$ decreases with the temperature. This is in accordance with what is expected of a composite material having as one of its components a polymeric material, such as the AC 50/70 binder, which for higher temperatures becomes less viscous. In addition, this decreasing is more accentuate for lower frequency. In the other hand, Fig. 5(b) presents the viscosity coefficient $\gamma$ as a function of frequency for three different temperatures of 25 (black), 35 (red) and $45^{\circ} \mathrm{C}$ (blue). The graph also illustrates a decreasing with the amount of frequency for all temperatures. Hence, 
it is consistent with the observation that the storage modulus increases and the dissipation modulus, which is associated with the viscosity of the material, decreases with frequency.

Furthermore, it was observed that the spectra of the load as a function of time presents apparent noise. This phenomenon can be explained as a correlation to the natural vibration modes of the beam [16]. As long as a pulse of load is applied to the beam, before a knew pulse be applied, it vibrates with its natural vibration mode, so that, the measured spectra is a composition of the both effect, the forced motion, due to the external applied load, and the beam natural vibration. This effect is more pronounced at higher temperatures. In Fig. 6, the sinusoidal spectra of the load is shown, as a function of time for two different frequencies of 1 and $3 \mathrm{~Hz}$, at temperature of $50{ }^{\circ} \mathrm{C}$. At the left column of this figure, three spectra of the sinusoidal charge ( $\mathrm{a}$ and $\mathrm{c}$ ) are registered, and at the right column, its corresponding excerpt ( $b$ and d), which represent the details inside the red rectangles in the left side column. The excerpts shows periodic behavior of the apparent noise, with an approximated period of $T_{1} \approx 0.0171 \mathrm{~s}$, which correspond to a frequency $f_{1}=58.5 \mathrm{~Hz}$. This oscillation around the mean value of the spectrum is an indication of the flexural wave propagation inside the beam, i.e., it is not a signal error.

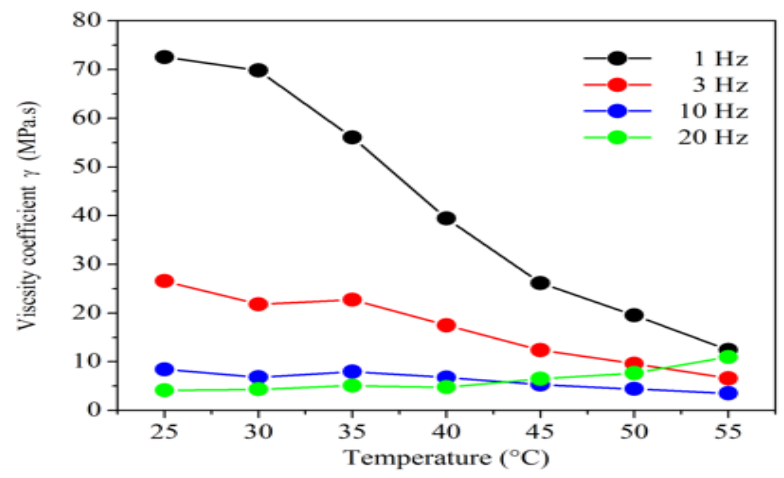

a)

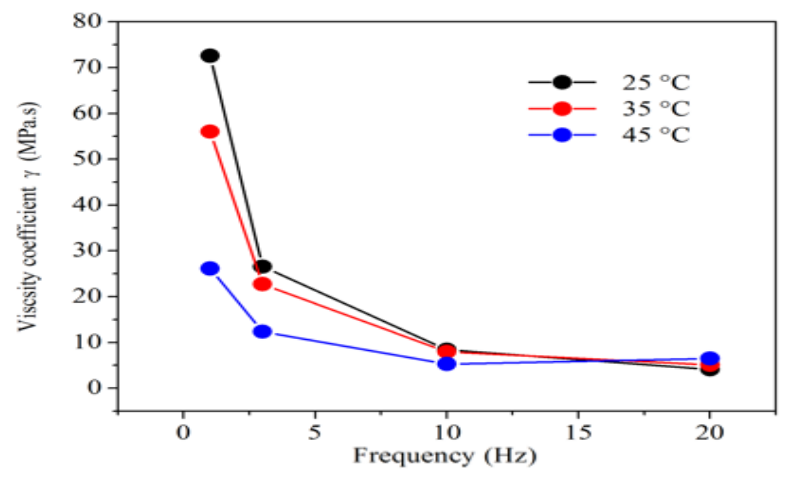

b)

Figure 5: a) Viscosity coefficient (MPa.s) as a function of temperature $\left({ }^{\circ} \mathrm{C}\right)$ for frequency of 1,3 , 10 and $20 \mathrm{~Hz} . \mathrm{b})$ Viscosity coefficient (MPa.s) as a function of frequency for different temperatures of 25,35 and $45^{\circ} \mathrm{C}$.
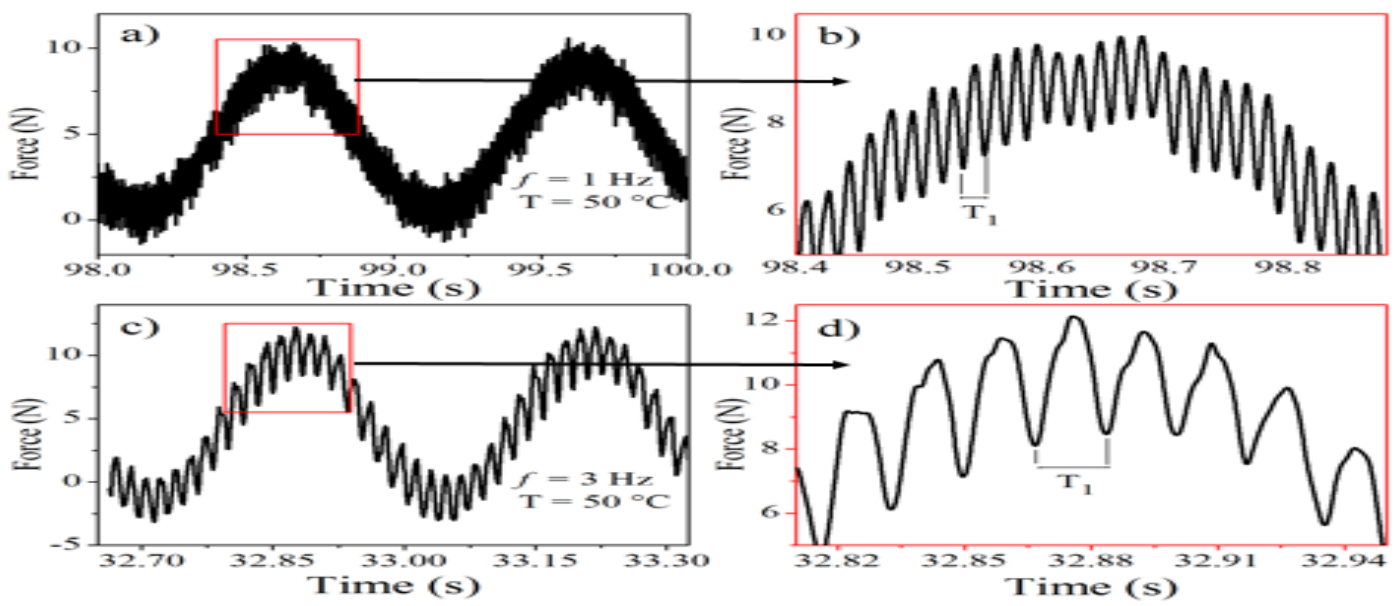

Figure 6: Spectra of force as a function of time. The excerpts at the right column show the apparent noise due to the natural vibration modes of the beam. 


\section{Conclusions}

In conclusion, the dynamical four-point bending test in the light of the Euler-Bernoulli theory was studied, taking into account the viscosity of the material via the Kelvin-Voigt model. This model was introduced in Euler-Bernoulli equation, substituting the Young modulus $E$ by the operator $(E$ $+\gamma \partial / \partial t)$, where $\gamma$ is an internal damping parameter. Beams were made with concrete asphalt, manufactured with sintered aggregate of calcined clay as the coarse aggregate, promising alternative to the lack of crushed stone in determined regions of the world, especially Amazon region, in northern Brazil. In these terms, the following conclusions can be drawn:

- From the stiffness and the phase angle measured with the four-point bending test, results indicated that, for fixed frequency, the stiffness decreases with the temperature, and for fixed temperature, the stiffness increases with frequency. According to the specialized literature, this behavior is quite acceptable;

- In addition, the viscoelastic coefficient could be calculated from the stiffness parameters and the developed equations. The internal damping parameter decreases with temperature and loading frequency;

- The apparent noise in the spectra of the force versus time is an indication of the flexural wave propagation inside the beam due its natural vibration modes produced by the load impact. Thus, the measured spectra is a composition of forced motion, due to the external applied load, and the beam natural vibration;

- The excerpts shows periodic behavior of the apparent noise, with an approximated period of $T_{1} \approx 0.0171 \mathrm{~s}$, which correspond to a frequency $f_{1}=58.5 \mathrm{~Hz}$. This oscillation around the mean value of the spectrum is an indication of the flexural wave propagation inside the beam.

\section{Acknowledgements}

The authors acknowledge financial support from the Brazilian funding agency, $\mathrm{CNPq}$ and FAPEAM.

\section{References}

[1] Pais J. C., Harvey J. H., EDS. Four-Point Bending. In: Proceedings of the Third Conference on Four-Point Bending; 2012 September 17-18, Davis, CA, USA.

[2] Pronk, A. C. Theory of the Four Point Dynamic Bending Test-Part I: General Theory. Report PDWW-96-008, Deft University of Technology, The Netherlands, 1996.

[3] M. Huurmann, A. C. Pronk. Theoretical analysis of the 4 point bending test. Proceedings of the 7th Int. RILEM Symposium Advanced Testing and Characterization of Bituminous Materials, Rhodes, Greece. 2009.

[4] Li, N., Pronk, A., Molenaar, A., van de Ven, M., Wu, S. Comparison of Uniaxial and Four-Point Bending Fatigue Tests for Asphalt Mixtures. Transportation Research Record. 2013, 2373:44-53.

[5] EN 12697-26. Bituminous mixtures: Test methods for hot mix asphalt. Part 26: Stiffness, 2012.

[6] AASHTO. Standard Specifications for Transportation Materials and Methods of Sampling and Testing. 23rd Edition, Part 2B. T321-03: Determining the fatigue life of compacted hot-mix asphalt (HMA) subjected to repeated flexural bending, AASHTO, Washington, D.C., 2003.

[7] Kim, Y. R., Baek, C., Underwood, B. S., Subramanian V., Guddati, N. Application of Viscoelastic Continuum Damage Model Based Finite Element Analysis to Predict the Fatigue Performance of Asphalt Pavements. Korean Soc. of Civ. Eng. 2008, 12(2):109-120. 
[8] Pronk, A. C. Partial Healing in Fatigue Tests on Asphalt Specimens. Road Materials and Pavement Design, 2001, 2(4):433-445.

[9] Losa, M., Leandri, P., Bacci, R. Mechanical and Performance-Related Properties of Asphalt Mixes Containing Expanded Clay Aggregate. Transportation Research Record, 2008. 2051:23-30.

[10] Lehmann, H. L., Adam, V. Use of Expanded Clay Aggregate in Bituminous Construction. Highway Research Board Proceedings. 1959, 38: 398-407.

[11] Aams, V., and Shah S. C. Evaluation of Open-Graded Plan-Mix Real Surfaces for Correction of Slippery Pavements. Transporta tion Research Record. 2008, 523: 88-96.

[12] Mallick R. B., Hooper FP, O'Brien S, Kashi M. Evaluation of Use of Synthetic Lightweight Aggregate in Hot-Mix Asphalt. Transportation Research Record. 2004, 1891: 1-7.

[13] Canestrari, FM, Bocci, G., Ferroti, G., Pasquini, P. Mechanical Caracterization of Environmentally Friendly Mixtures. Proceeding of the International Conference on Advanced Characterization of Pavement and Soil Engineering Materials, Greece, June 2007, 1643-1652.

[14] Lytto, R. L. Characterizing Asphalt Pavements for Performance. Transportation Research Record: Journal of the Transportation Research Board. 2000, 1723(1): 5-16.

[15] Love, A. E. H. A Treatise on the Mathematical Theory of Elasticity. Cambridge University Press (1927). Reprinted New York: Dover; 1963.

[16] Graff, K. F. Wave Motion in Elastic Solids. New York: Dover; 1991.

[17] Terhi, K. P. Complex Modulus Characterization of Asphalt Concrete. In: Kim YR, ed. Modeling of Asphalt Concrete. ASCE Press-Mc Graw Hill. 2009. p. 89-119.

[18] Findley, W. N., Lai, J. S., and Onaran, K. Creep and Relaxation of Nonlinear Viscoelastic Materials. New York: Dover; 1989.

[19] Arfken, G. Mathematical Methods for Physics. New York: Academic Press; 1970.

[20] Melo, J. V. S. Desenvolvimento e Estudo do Comportamento Reológico e Desempenho Mecânico de Concretos Asfálticos Modificados com Nanocompósitos, 2014. Universidade Federal de Santa Catarina (in Portuguese).

\footnotetext{
*Corresponding author.

E-mail address: julianospinola10@gmail.com
} 